\title{
CMEARTICLE
}

\section{Clinics in diagnostic imaging (186)}

Li Ching Lau ${ }^{1}$, MBBS, FRCR, Hui Liang Koh${ }^{2}$, MBBS, FRCR, Wei Luen James Yip ${ }^{3}$, MBBS, MRCP, Ching Ching Ong'2, MBBS, FRCR

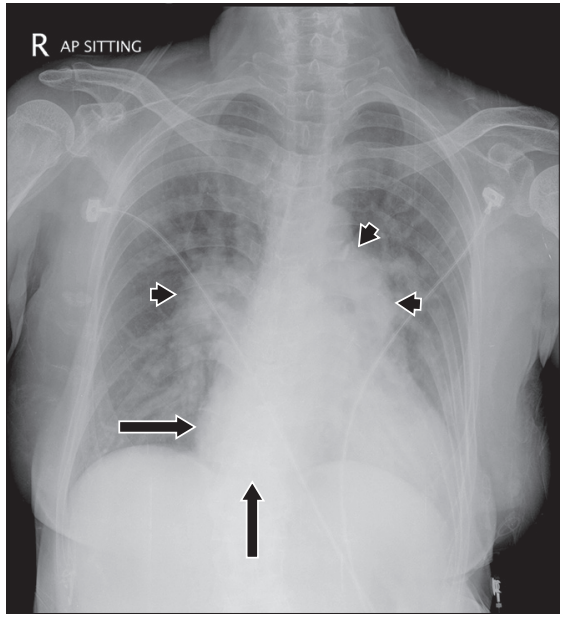

Fig. 1 Frontal chest radiograph

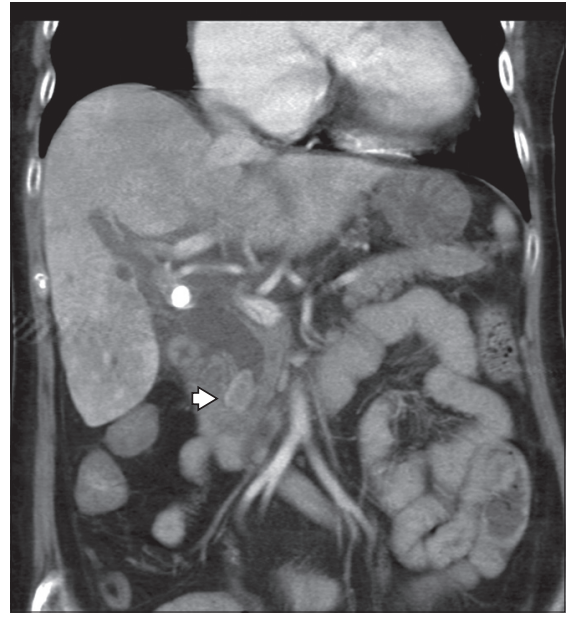

Fig. 2 Coronal contrast-enhanced CT image of the abdomen.

\section{CASE PRESENTATION}

A 61-year-old Chinese woman presented to the emergency department with fever, vomiting and anorexia of three days' duration. She had a past medical history of hypertension, hyperlipidaemia and a previous cerebrovascular accident.

On examination, the patient was toxic looking, confused and jaundiced. Her vital signs were as follows: temperature $40.5^{\circ} \mathrm{C}$, blood pressure $134 / 67 \mathrm{mmHg}$, respiratory rate 20 breaths per minute, pulse rate 149 beats per minute and oxygen saturation $98 \%$ on room air. Physical examination revealed soft S1 and loud

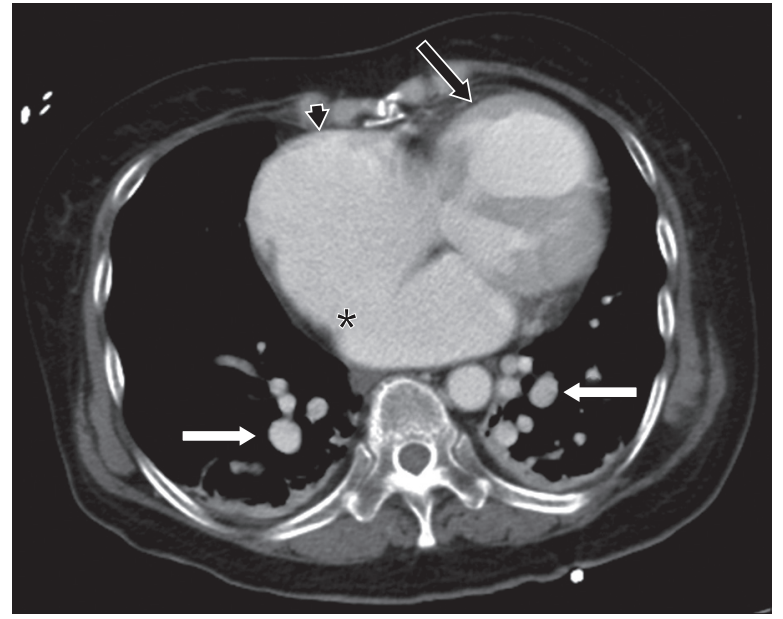

Fig. 3 Axial contrast-enhanced CT image of the appended lower chest

S2 heart sounds, with no cardiac murmur. There were crepitations in the lung bases and tenderness over the right hypochondrium. Initial blood investigations showed leucocytosis, conjugated hyperbilirubinaemia, and elevated alkaline phosphatase and transaminase levels. Electrocardiography showed right bundle branch block with right axis deviation.

Chest radiography (Fig. 1) was performed, followed by computed tomography (CT) of the abdomen and pelvis (Figs. $2 \& 3$ ) to evaluate the suspected hepatobiliary sepsis. What do the images show? What is the diagnosis? 


\section{IMAGE INTERPRETATION}

Anterior-posterior chest radiograph (Fig. 1) shows cardiomegaly with probable dilatation of the right atrium (arrows). The central pulmonary arteries are dilated (arrowheads), suggesting pulmonary arterial hypertension. No pruning of pulmonary arteries was seen.

The CT images of the abdomen and pelvis show biliary obstruction secondary to a calculus in the distal common bile duct (arrowhead, Fig. 2). There are also incidental findings of an atrial septal defect (ASD) measuring at least 27 mm (asterisk, Fig. 3), as well as dilatation of the right atrium (black arrowhead), right ventricle (black arrow) and pulmonary arteries (white arrows).

\section{DIAGNOSIS}

Atrial septal defect with pulmonary arterial hypertension.

\section{CLINICAL COURSE}

The patient required intubation and intensive care on admission. She also developed complications of Gram-negative septicaemic shock, pneumonia and acute kidney injury. A cardiologist reviewed her in the intensive care unit. Echocardiography that was performed confirmed a large secundum ASD with left-to-right shunt flow, severe right ventricular systolic dysfunction, severe tricuspid regurgitation and severe pulmonary hypertension. Pulmonary artery systolic pressure (PASP) was $70 \mathrm{mmHg}$ and left ventricle ejection fraction was $55 \%$. She was unlikely to have Eisenmenger's syndrome, as her oxygen saturation level was normal on room air.

The patient initially responded to the treatment of hydration, intravenous antibiotics and biliary stenting. However, her condition subsequently deteriorated when she developed critical illness neuropathy and recurrent desaturations. She eventually passed away.

\section{DISCUSSION}

Our patient was incidentally diagnosed with ASD in late adulthood when she presented with hepatobiliary sepsis. The presence of a large ASD with severe pulmonary hypertension, in this case, was deemed a significant contributor to her poor clinical outcome. ASD can present at any age and is also the most common congenital heart disease presenting in adulthood. ${ }^{(1,2)}$ This article aimed to highlight the imaging features of ASD, with special emphasis on the routine chest radiograph. The pathophysiology and clinical manifestations of ASD were also briefly discussed.

An ASD is an abnormal communication between the left and right atria of the heart. It produces a constant left-to-right interatrial shunt flow and also intermittent right-to-left shunt flow from transient increases in right atrial pressure during a Valsalvalike activity such as forceful coughing. This right-to-left shunt flow can result in paradoxical embolisation. A patent foramen ovale, on the other hand, produces only intermittent right-to-left interatrial shunt flow. ${ }^{(3)}$ Constant left-to-right shunting due to the ASD may result in right heart dilatation and pulmonary arterial hypertension over time. The magnitude and direction of shunting are related to the defect size and relative diastolic filling properties of the left and right ventricles. ${ }^{(2)}$ For example, a left-to-right shunt is increased with left ventricular hypertrophy or mitral stenosis. ${ }^{(4)}$ The majority of adults with ASDs remain asymptomatic. Early signs may be picked up on health screening examinations, electrocardiography or chest radiography. Auscultation may reveal a faint to moderately loud systolic ejection murmur best heard at the upper left sternal border; wide split fixed S2; absent thrill; and a barely audible to faint diastolic flow rumble at the lower left sternal border. ${ }^{(4)}$ When patients with ASDs eventually become symptomatic, they may commonly present with symptoms such as exertional dyspnoea, decreased effort tolerance and palpitations from arrhythmias. ${ }^{(2)}$

Radiographic evidence of ASD is often subtle. The normal cardiomediastinal outline is reviewed in Fig. 4. The right atrium forms the right cardiac border. The right ventricle, an anterior structure located just underneath the sternum, forms the inferior border of the heart on the frontal chest radiograph. The left atrium is a posterior structure located just below the carina; only its appendage forms part of the left heart border. The left ventricle forms the left heart border. The normal upper limit of the diameter of the right interlobar pulmonary artery is $15 \mathrm{~mm}$ in women and $16 \mathrm{~mm}$ in men. ${ }^{(5)}$

On the chest radiograph, the first sign of underlying ASD is right heart dilatation. Increased convexity and enlargement of the right heart border suggest right atrial dilatation. When the right ventricle dilates, the left ventricle is displaced superolaterally, which results in increased convexity of the left heart border and cardiac apex. ${ }^{(6)}$ Long-standing ASD results in pulmonary hypertension (PH), which is an abnormal elevation of pressure in the pulmonary circulation (mean pulmonary arterial pressure $>25 \mathrm{mmHg}$ ). Features of $\mathrm{PH}$ on chest radiographs include central pulmonary artery dilatation (due to increased pulmonary flow), pruning of the peripheral

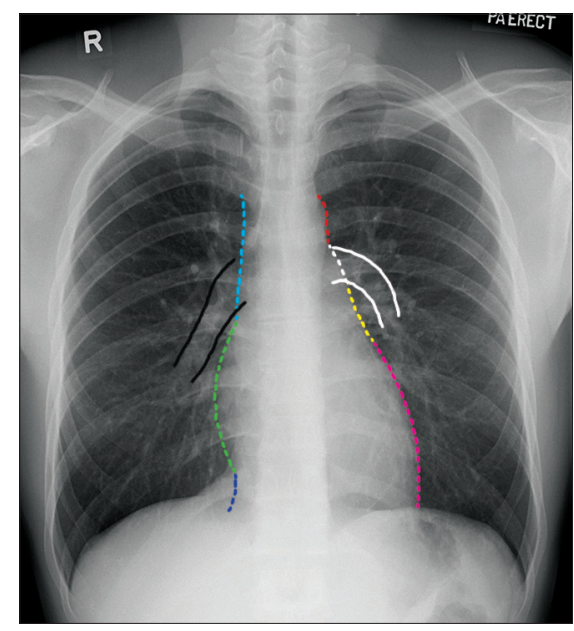

Fig. 4 Normal frontal chest radiograph shows the right and left mediastinal outlines. The right mediastinal outline is formed by the superior vena cava (cyan dashed line), right pulmonary artery (black solid line), right atrium (green dashed line) and inferior vena cava (blue dashed line). The left mediastinal outline is formed by the aortic knuckle (red dashed line), main pulmonary artery (white dashed line), left pulmonary artery (white solid line), left atrial appendage (yellow dashed line) and left ventricle (magenta dashed line). The right atrium should only show mild convexity. The normal size of the pulmonary arteries has been likened to the little fingers of adults. 
Table I. Classification of pulmonary hypertension, adapted from the Dana Point classification system. ${ }^{(7)}$

\begin{tabular}{|c|c|}
\hline Group & Classification \\
\hline 1 & $\begin{array}{l}\text { Pulmonary arterial hypertension } \\
\text { - Idiopathic } \\
\text { - Heritable } \\
\text { - Drug and toxin induced } \\
\text { - Associated with: connective tissue disease, HIV infection, portal hypertension, congenital heart diseases and schistosomiasis } \\
\text { Pulmonary veno-occlusive disease and/or pulmonary capillary haemangiomatosis } \\
\text { Persistent pulmonary hypertension of the newborn }\end{array}$ \\
\hline 2 & $\begin{array}{l}\text { Pulmonary hypertension due to left heart disease } \\
\text { - Left ventricular systolic/diastolic dysfunction } \\
\text { - Valvular disease } \\
\text { - Left heart inflow/outflow tract obstruction }\end{array}$ \\
\hline 3 & $\begin{array}{l}\text { Pulmonary hypertension due to lung diseases and/or hypoxia } \\
\text { - Chronic obstructive pulmonary disease } \\
\text { - Interstitial lung disease } \\
\text { - Other pulmonary diseases with mixed restrictive and obstructive pattern } \\
\text { - Sleep-disordered breathing } \\
\text { - Alveolar hypoventilation disorders } \\
\text { - Chronic exposure to high altitude } \\
\text { - Developmental lung diseases }\end{array}$ \\
\hline 4 & Chronic thromboembolic pulmonary hypertension \\
\hline 5 & $\begin{array}{l}\text { Pulmonary hypertension with unclear multifactorial mechanisms } \\
\text { - Haematological disorders } \\
\text { - Systemic disorders } \\
\text { - Metabolic disorders } \\
\text { - Others }\end{array}$ \\
\hline
\end{tabular}

HIV: human immunodeficiency virus

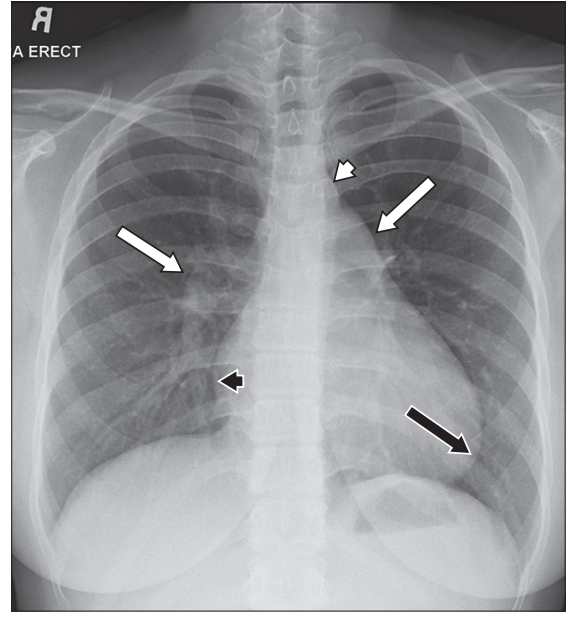

Fig. 5 A 19-year-old woman presented with shortness of breath on exertion and palpitations. Frontal chest radiograph shows dilated central pulmonary arteries (white arrows) with a small aortic knuckle (white arrowhead), which suggests a left-to-right shunt. There is also right atrial dilatation (black arrowhead) and elevation of the cardiac apex (black arrow) due to right ventricular dilatation. A large secundum atrial septal defect (ASD; $29 \mathrm{~mm} \times 35 \mathrm{~mm}$ ) and elevated pulmonary artery systolic pressure (PASP) of $44 \mathrm{mmHg}$ were seen on echocardiography (not shown).

arteries and increased diameter of the right interlobar artery (15 $\mathrm{mm}$ in women and $16 \mathrm{~mm}$ in men), as measured from its lateral aspect to the interlobar bronchus. In addition, a small aortic knuckle can be seen in patients with ASD, a manifestation of decreased systemic flow.

There are many causes of $\mathrm{PH}$ and it is important to look for clues to the underlying causes on chest radiographs, such as interstitial lung disease, emphysema and chest wall deformities. The Fifth World Symposium on Pulmonary Hypertension held in

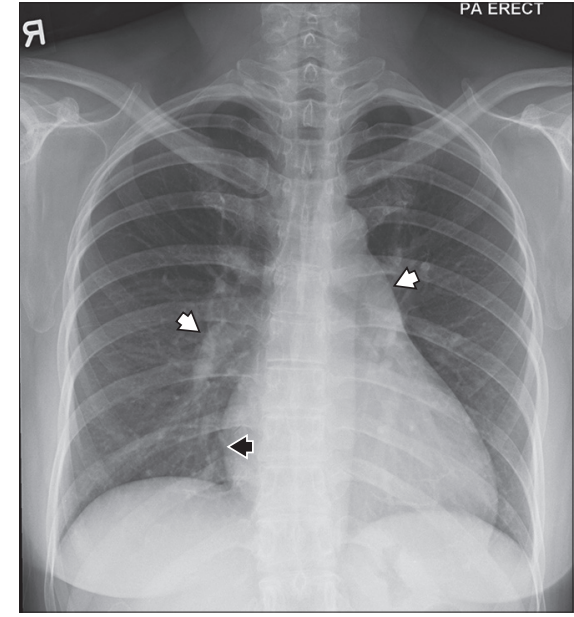

Fig. 6 A 46-year-old lady presented with palpitations. Frontal chest radiograph shows dilatation of the right atrium (black arrowhead) and central pulmonary arteries (white arrowheads). A large secundum ASD $(25 \mathrm{~mm} \times 30 \mathrm{~mm})$ and elevated PASP of $52 \mathrm{mmHg}$ were seen on echocardiography (not shown).

Nice, France, in 2013 updated the clinical classification of $\mathrm{PH}$ in the following groups: disorders that cause pulmonary arterial hypertension (Group 1); PH due to left heart disease (Group 2), $\mathrm{PH}$ due to chronic lung disease or hypoxia (Group 3); chronic thromboembolic pulmonary hypertension (Group 4); and $\mathrm{PH}$ due to unclear multifactorial mechanisms (Group 5). ${ }^{(7)}$ The classification of $\mathrm{PH}$ is listed in Table I. Case examples of ASD are illustrated in Figs. 5 \& 6. Comparison with previous radiographs may be helpful in identifying subtle and gradual changes in the size and configuration of the right heart chambers and central pulmonary arteries. 


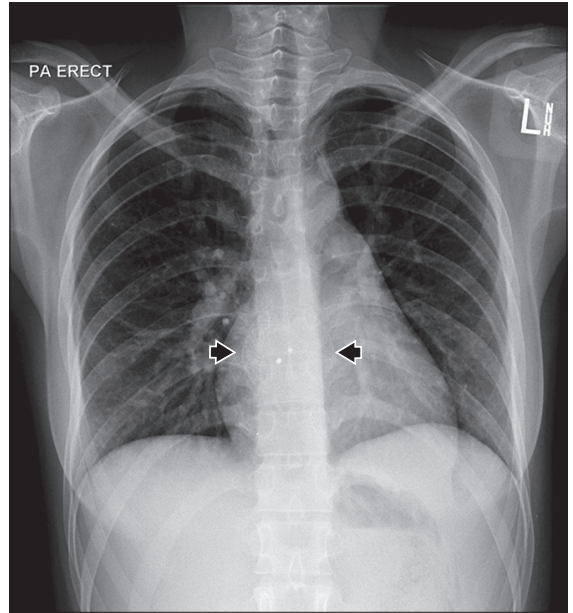

Fig. 7 A 20-year-old woman was asymptomatic with an incidental finding of a heart murmur. Echocardiography (not shown) revealed a large secundum ASD $(20 \mathrm{~mm} \times 20 \mathrm{~mm})$, elevated PASP of $41 \mathrm{mmHg}$, and mitral valve prolapse, which was the cause of the murmur. She underwent ASD closure with an Amplatzer septal occluder (area between black arrowheads). Frontal chest radiograph shows the typical double-disc configuration of the Amplatzer septal occluder device. There are also features of dilatation of the right heart and pulmonary arteries.

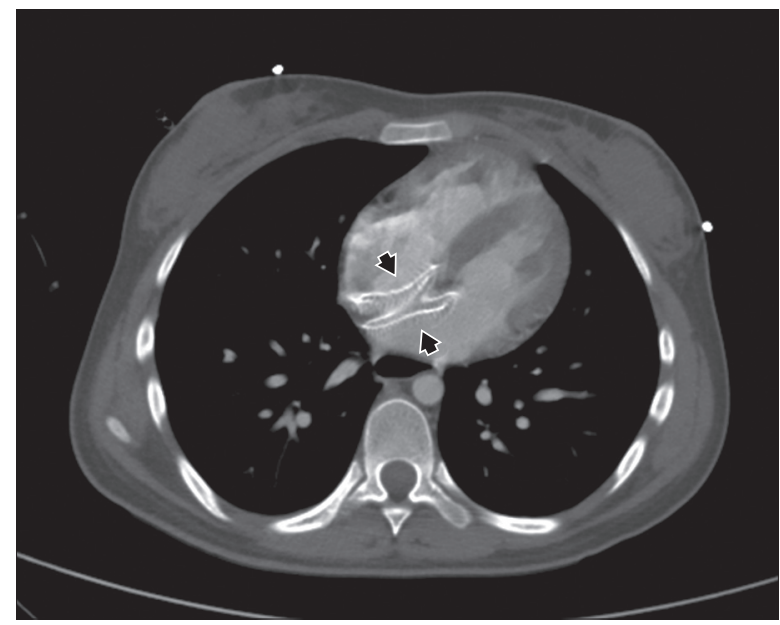

Fig. 8 Axial contrast-enhanced CT image of the same patient from Fig. 7 The Amplatzer septal occluder (area between black arrowheads) is in situ, apposing the atrial septal wall on each side of the defect.

The diagnostic modality of choice for ASD is echocardiography, as it provides both structural and functional information. ${ }^{(8)}$ Transthoracic echocardiography may be limited in assessing the right ventricle due to poor acoustic windows in some patients. Transoesophageal echocardiography may be performed to obtain a better acoustic window, but it is invasive in nature. Cardiovascular magnetic resonance (CMR) imaging, CT and diagnostic cardiac catheterisation are alternative modes of imaging. CMR imaging is the gold standard for the assessment of right ventricular volumes and function. It also allows for shunt quantification $(\mathrm{Qp} / \mathrm{Q}$ s ratio; ratio of total pulmonary blood flow to total systemic blood flow) by using velocity flow mapping. A Qp/Qs ratio of 1:1 is normal and usually indicates that there is no shunting. CT and CMR imaging both have the advantage of allowing the visualisation of pulmonary venous return, which is especially important in excluding a concomitant partial anomalous pulmonary venous drainage.

Haemodynamically significant ASDs are associated with increased morbidity and mortality. ${ }^{(2)}$ Early detection and closure of significant ASDs can help reduce morbidity by preventing some of the associated complications. These complications include arrhythmias, paradoxical embolism, stroke, brain abscess, pulmonary hypertension, pulmonary artery aneurysm, right ventricle failure and Eisenmenger's syndrome. ${ }^{(8,9)}$ Transcatheter device closure of suitable secundum ASDs (Fig. 7 \& 8 ) is now an available option that is associated with less morbidity than open surgical closure. ${ }^{(10)}$

\section{ACKNOWLEDGEMENTS}

The authors would like to acknowledge Dr Lynette Teo, Dr Lee Chin Hwee and all colleagues at National University Hospital, Singapore, who were involved in the care of our patient.

ABSTRACT We report a case of a 61-year-old woman with a large atrial septal defect (ASD) that was detected incidentally on chest radiography and computed tomography when she presented with sepsis. Echocardiography confirmed a large secundum ASD with left-to-right shunt flow, right heart dilatation and severe pulmonary hypertension. The patient had a poor clinical outcome despite intensive care and eventually passed away. Haemodynamically significant ASDs have a known association with increased morbidity and mortality, and their early detection and closure cannot be understated. This article aimed to highlight the imaging features of ASD, with special emphasis on the routine chest radiograph. The pathophysiology and clinical manifestations of ASD are also briefly discussed.

Keywords: atrial septal defect, cardiomegaly, chest $x$-ray, pulmonary hypertension, septal occluder device

\section{REFERENCES}

1. Rojas CA, El-Sherief A, Medina HM, et al. Embryology and developmental defects of the interatrial septum. AJR Am J Roentgenol 2010; 195:1100-4.

2. Webb G, Gatzoulis MA. Atrial septal defects in the adult: recent progress and overview. Circulation 2006; 114:1645-53.

3. Kedia G, Tobis J, Lee MS. Patent foramen ovale: clinical manifestations and treatment. Rev Cardiovasc Med 2008; 9:168-73.

4. Frank JE, Jacobe KM. Evaluation and management of heart murmurs in children. Am Fam Physician 2011; 84:793-800.

5. Peña E, Dennie C, Veinot J, Muñiz SH. Pulmonary hypertension: how the radiologist can help. Radiographics 2012; 32:9-32.

6. Cook AL, Hurwitz LM, Valente AM, Herlong JR. Right heart dilatation in adults: congenital causes. AJR Am J Roentgenol 2007; 189:592-601.

7. Simonneau G, Gatzoulis MA, Adatia I, et al. Updated clinical classification of pulmonary hypertension. J Am Coll Cardiol 2013; 62(25 Suppl):D34-41.

8. Martin SS, Shapiro EP, Mukherjee M. Atrial septal defects - clinica manifestations, echo assessment, and intervention. Clin Med Insights Cardiol 2014; 8(Suppl 1):93-8.

9. Tartan Z, Cam N, Ozer N, Kaşikçioğlu H, Uyarel H. Giant pulmonary artery aneurysm due to undiagnosed atrial septal defect associated with pulmonary hypertension. Anadolu Kardiyol Derg 2007; 7:202-4.

10. Quek SC, Hota S, Tai BC, Mujumdar S, Tok MY. Comparison of clinical outcomes and cost between surgical and transcatheter device closure of atrial septal defects in Singapore children. Ann Acad Med Singapore 2010; 39:629-33. 


\section{SINGAPORE MEDICAL COUNCIL CATEGORY 3B CME PROGRAMME} (Code SMJ 201805B)

Question 1. Regarding the clinical auscultation findings of atrial septal defects (ASDs):

(a) ASDs do not cause cardiac murmurs.

(b) ASDs can cause a systolic ejection murmur that is best heard at the upper left sternal border.

(c) ASDs do not cause continuous machinery murmurs.

(d) ASDs do not cause widely split fixed S2.

Question 2. Regarding ASD:

(a) It is the most common congenital heart disease presenting in adulthood.

(b) Early detection and closure of haemodynamically significant ASDs can help to reduce morbidity and mortality.

(c) The diagnostic modality of choice is cardiovascular magnetic resonance imaging.

(d) Transcatheter device closure is now an available treatment option.

Question 3. Regarding the haemodynamics of ASDs:

(a) It can allow right-to-left interatrial shunt flow, which explains paradoxical embolism.

(b) It usually produces left-to-right interatrial shunt flow, because the left atrium has higher pressure than the right atrium.

(c) Most ASDs are haemodynamically well tolerated and remain asymptomatic into adulthood.

(d) A left-to-right interatrial shunt flow is decreased with left ventricular hypertrophy.

Question 4. Regarding the imaging features of ASDs on chest radiographs:

(a) Imaging features include right atrial dilatation, right ventricular dilatation and pulmonary arterial dilatation.

(b) The first sign of ASD is pulmonary arterial dilatation.

(c) A large aortic knuckle is seen due to increased systemic flow.

(d) Atrial septal occluder devices are visible on the chest radiograph.

Question 5. The following are known complications of ASDs:
(a) Stroke.
(b) Arrhythmia and palpitations.
(c) Eisenmenger's syndrome.
(d) Heart failure.

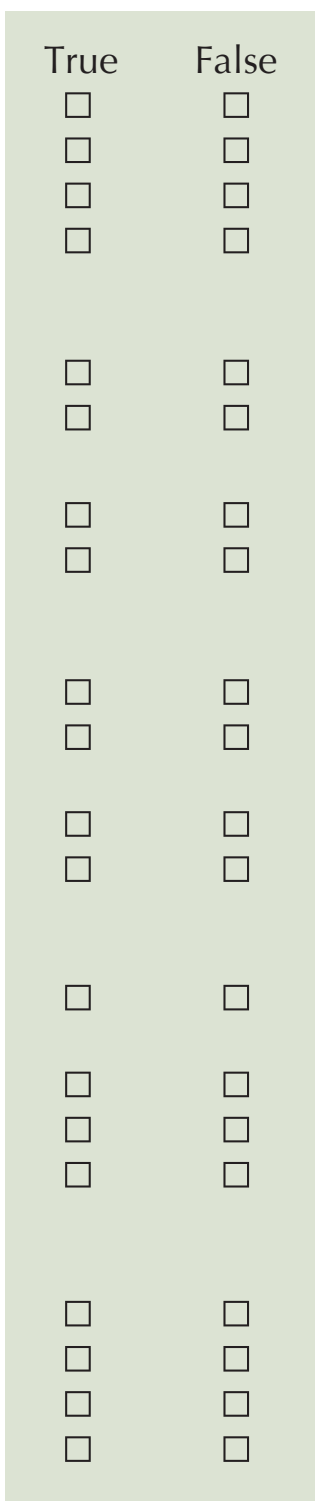

\section{Doctor's particulars:}

Name in full:

MCR no.:

Specialty:

Email:

\section{SUBMISSION INSTRUCTIONS:}

Visit the SMJ website: http://www.smj.org.sg/current-issue and select the appropriate quiz. You will be redirected to the SMA login page.

For SMA member: (1) Log in with your username and password (if you do not know your password, please click on 'Forgot your password?'). (2) Select your answers for each quiz and click 'Submit'.

For non-SMA member: (1) Create an SMJ CME account, or log in with your SMJ CME username and password (for returning users). (2) Make payment of SGD 21.40 (inclusive of $7 \%$ GST) via PayPal to access this month's quizzes. (3) Select your answers for each quiz and click 'Submit'.

\section{RESULTS:}

(1) Answers will be published online in the SMJ July 2018. (2) The MCR numbers of successful candidates will be posted online at the SMJ website by 5 July 2018. (3) Passing mark is $60 \%$. No mark will be deducted for incorrect answers. (4) The SMJ editorial office will submit the list of successful candidates to the Singapore Medical Council. (5) One CME point is awarded for successful candidates. (6) SMC credits CME points according to the month of publication of the CME article (i.e. points awarded for a quiz published in the December 2017 issue will be credited for the month of December 2017, even if the deadline is in January 2018).

Deadline for submission: (May 2018 SMJ 3B CME programme): 12 noon, 28 June 2018. 